\title{
Effects of seamounts on an interplate earthquake at the Suruga trough, Japan
}

\author{
Yoshimori Honkura $^{1}$, Yoshiharu Nagaya ${ }^{2}$, and Hidekuni Kuroki ${ }^{1 *}$ \\ ${ }^{1}$ Department of Earth and Planetary Sciences, Tokyo Institute of Technology, 2-12-1 Ookayama, Tokyo 152-8551, Japan \\ ${ }^{2}$ Hydrographic Department, Maritime Safety Agency, 5-3-1 Tsukiji, Tokyo 104-0045, Japan
}

(Received February 5, 1999; Revised May 14, 1999; Accepted June 18, 1999)

\begin{abstract}
Detailed magnetic surveys carried out in the Suruga trough area, where the Philippine Sea plate subducts beneath Japan, revealed some local magnetic anomalies on the overriding plate side. We first show that these anomalies reflect seamounts sitting on and subducting with the Philippine Sea plate, since no magnetic sources corresponding to the anomalies are identified in the seafloor topography. An important issue to be addressed is how these seamounts affect the generation of a great interplate earthquake at the Suruga trough (often referred to as the Tokai earthquake). So we made a numerical simulation of earthquake generation, applying the rate- and state-variable friction law to the plate interface. Here we incorporated the seamounts in the simulation as an additional normal stress exerted locally to the interface. We then found how the seamounts affect the generation of an interplate earthquake depends on whether or not they are located in the seismogenic zone. The most notable effect is that the amount of slip immediately before the main shock, often called a pre-slip, tends to be enhanced if they are located inside the zone.
\end{abstract}

\section{Introduction}

Recently, much attention has been paid to the possible roles of seamounts subducting with an oceanic plate within the characteristics of earthquake generation at the plate interface (Cloos and Shreve, 1996; Scholz and Small, 1997). Two different mechanisms for seamount effects have so far been proposed. In one mechanism (Cloos and Shreve, 1996), the effect of seamounts is supposed to be controlled by the amount of sediment. If the amount of sediment is not sufficient at the trench, the seamount is decapitated at the trench, resulting in a rather small earthquake. If the amount of sediment is sufficient to cover a seamount at the trench, the seamount can subduct with the sediment at a considerable depth and, eventually, the seamount behaves as an asperity for a large thrust earthquake (Lay and Kanamori, 1981). In the other mechanism (Scholz and Campos, 1995; Scholz and Small, 1997), the effect of the seamount is realized through an additional normal stress exerted at the plate interface by seamount subduction. In this case, the background state of plate coupling is a controlling factor for the generation of earthquakes; in the decoupled state, the additional normal stress alters the state locally, resulting in local seismicity, and in the coupled state, it strengthens the coupling, resulting in a longer recurrence interval of a large earthquake.

In these arguments, a large-scale seamount which can be detected by a gravity anomaly is considered (Scholz and Small, 1997). In this letter, however, we examine some possible effects of a smaller-scale seamount, not on the overall characteristics of earthquake generation but on the generation

*Now at Seismological and Volcanological Department, Japan Meteorological Agency, Tokyo 100-0004, Japan.

Copy right (C) The Society of Geomagnetism and Earth, Planetary and Space Sciences (SGEPSS); The Seismological Society of Japan; The Volcanological Society of Japan; The Geodetic Society of Japan; The Japanese Society for Planetary Sciences. of an individual yet large earthquake within the framework of an earthquake cycle at the subduction zone. More specifically, our concern is to find some characteristics which have remained unnoticed.

We pay our particular attention to the Suruga trough area, where the Philippine Sea plate subducts beneath Japan and large interplate earthquakes have recurred. Also, as we show in the next section, small-scale seamounts seem to lie on the subducting Philippine Sea plate in the Suruga trough area. We therefore examine whether these seamounts affect the generation of a large interplate earthquake, often referred to as the Tokai earthquake (Ishibashi, 1981), and if they do, we next examine what are the most important effects.

For this purpose, we made a numerical simulation of earthquake generation in the Suruga trough area, applying the rate- and state-variable friction law (Dieterich, 1979a, 1981; Ruina, 1983; Scholz, 1998) to the plate interface. This friction law has shown a variety of characteristics of an interplate earthquake such as its recurrence rate, seismic coupling of the interface, and pre-slip before the main shock (Dieterich, 1979b; Tse and Rice, 1986; Stuart, 1988; Rice, 1993; BenZion and Rice, 1995; Kato and Hirasawa, 1996, 1997).

\section{Magnetic Anomalies in the Suruga Bay}

We first show how we could find small-scale seamounts at the Suruga trough, central Japan, where a large thrust earthquake, often referred to as the Tokai earthquake, has been supposed to occur soon (Ishibashi, 1981). The magnetic anomaly map derived from the nationwide aeromagnetic surveys over the Japanese region provides valuable information on regional-scale magnetic anomalies. In fact, a positive anomaly prevails in the Suruga trough area, seemingly as part of the northern extension of positive anomalies over the Izu-Bonin arc (Honkura et al., 1991), where many volcanoes scatter in the north-south direction. However, magnetic 


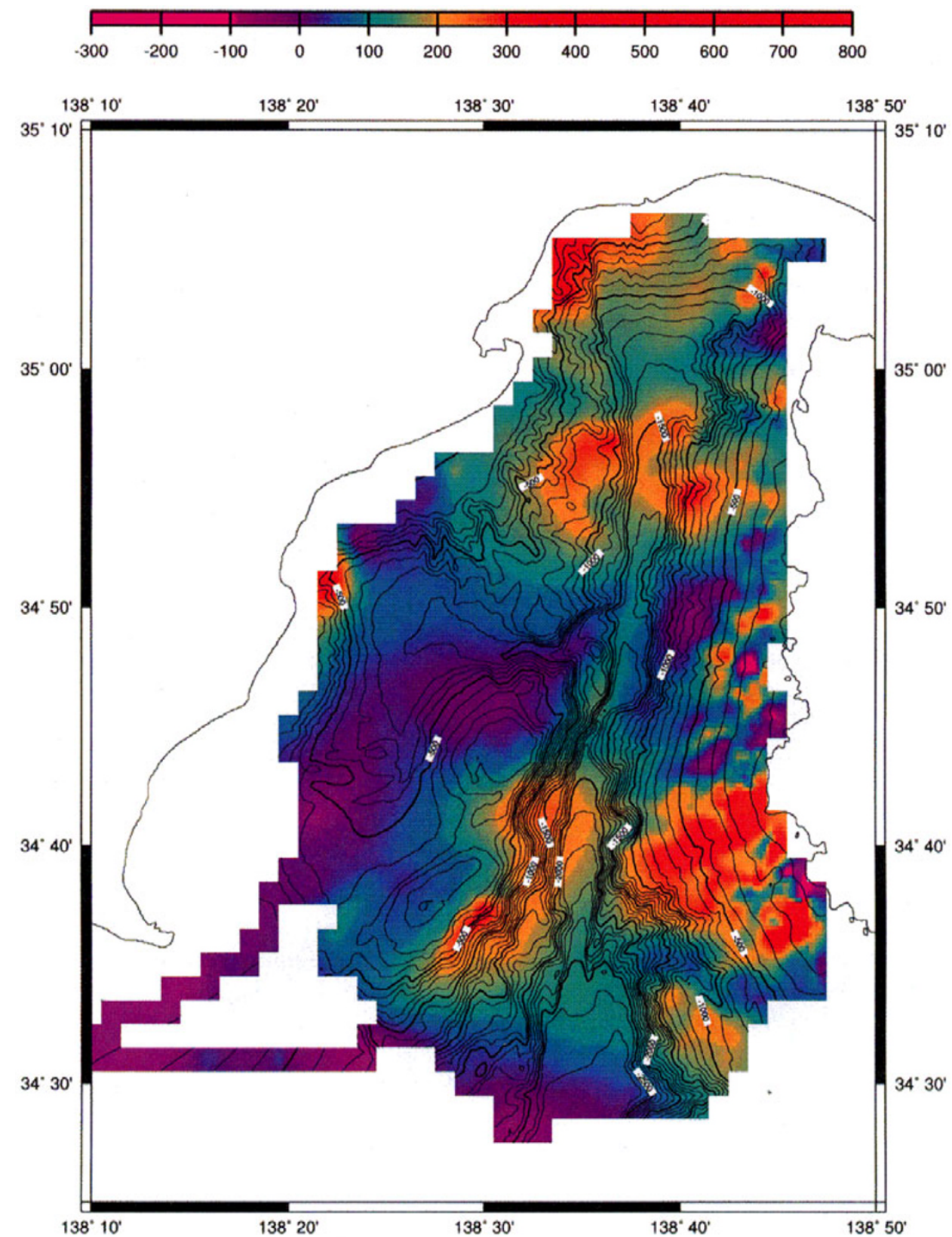

Fig. 1. Distribution of magnetic anomalies in the Suruga trough area, central Japan, as derived from detailed ship-borne magnetic surveys. The color code shows the amount of anomaly in nanoteslas; the reddish color indicates positive anomalies and the bluish color negative anomalies. Contours show the seafloor topography in units of $100 \mathrm{~m}$. A deep trough is seen in the north-south direction; this is called the Suruga trough. The Philippine Sea plate subducts at this trough in the northwest direction. Clear correspondence can be seen between a pair of positive anomalies and a pair of banks in the southwestern area.

anomalies corresponding to local features such as small-scale seamounts, are best delineated through ship-borne magnetic surveys. Such detailed surveys were carried out in the Suruga trough area (see Fig. 1) by the Hydrographic Department of the Maritime Safety Agency.

As we expected, fine-scale magnetic anomalies could be disclosed as shown in Fig. 1. The reddish color indicates positive anomalies and the bluish color negative anomalies. Here we pay special attention to one of the positive anomalies seen on the west side of the Suruga trough running in the north-west direction; the southern-most one seems to consist of two separate positive anomalies. If we compare this fea- ture with the detailed topographic contours in the same figure, clear correspondence between the magnetic and topographic features can be easily recognized. More specifically, positive magnetic anomalies seem to be located in the southeast of two small-scale banks. At a glance, one may suppose that the positive anomalies stem from topographic relief. If this is the case, the topographic relief should roughly coincide with pole-reduced magnetic anomalies shown in Fig. 2. Contrary to such expectations, the pole-reduced anomalies are still on the southeastern side of the banks, as can be more clearly recognized in the bird's-eye view shown in Fig. 3. In this figure, another less marked anomaly is seen further north 


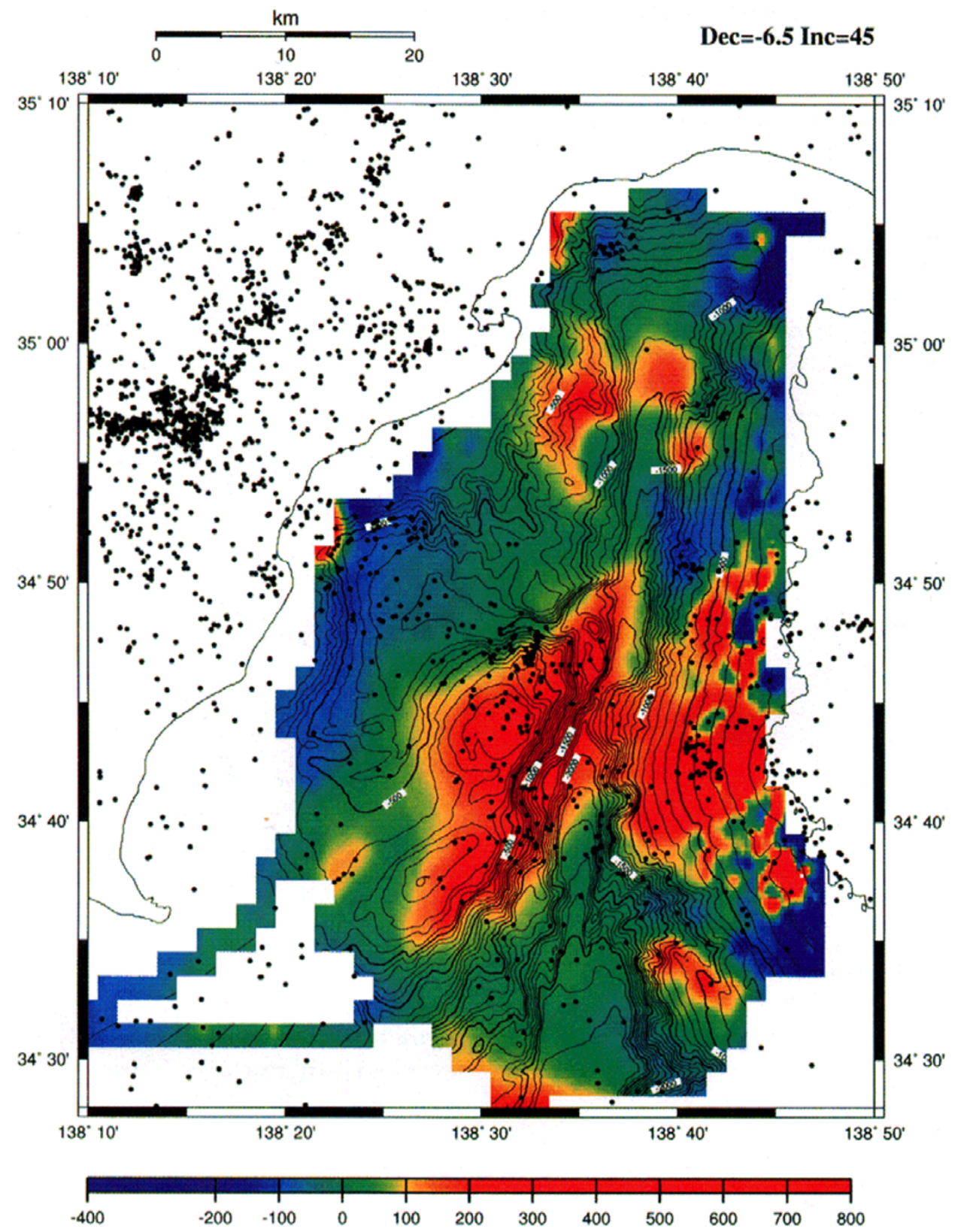

Fig. 2. Distribution of magnetic anomalies reduced to the north pole of the Earth; if this area is located in the north pole region, magnetic anomalies will be seen like in this figure. Roughly speaking, a magnetic source should be located beneath a pole-reduced magnetic anomaly. Small dots denote the epicenters of small earthquakes determined by NIED for the period from January 1, 1986 to December 20, 1996.

and a corresponding bank-like structure can be identified in the topographic view; it is separated from the main banks by a channel.

Our preliminary interpretation of these magnetic anomalies shows that the banks are not the sources of the magnetic anomalies. Then we are obliged to interpret the observed magnetic anomalies as indicating buried magnetic bodies, which are most probably small-scale seamounts sitting on the subducting plate, because the overriding plate mainly consists of accretionary sediments (Le Pichon et al., 1996) and their magnetization is weak. In fact, this is the reason why we cannot see a clear magnetic signature for the banks. One may then ask the following question: are these two kinds of feature a mere coincidence? In this respect, we note the fact that the banks are located in the northwest of the presumed subducting seamounts. This is the direction in which the Philippine Sea plate moves against the overriding plate (Seno, 1977), and we can understand the relation on the analogy of the Tibetan Plateau caused by the collision with the Indian Continent (Molnar and Tapponier, 1975; Molnar et al., 1993). In short, the banks behind the seamounts are likely to have been caused by the collision of the seamounts with the accretionary sediments. More, indirect evidence for the existence of seamounts is the occurrence of small earthquakes of magnitudes ranging mostly between 1.0 and 3.0 in the vicinity of the magnetic anomalies (see Fig. 2). This seismicity can be interpreted in terms of either a seamount decapitation process (Cloos and Shreve, 1996) or an enhanced 


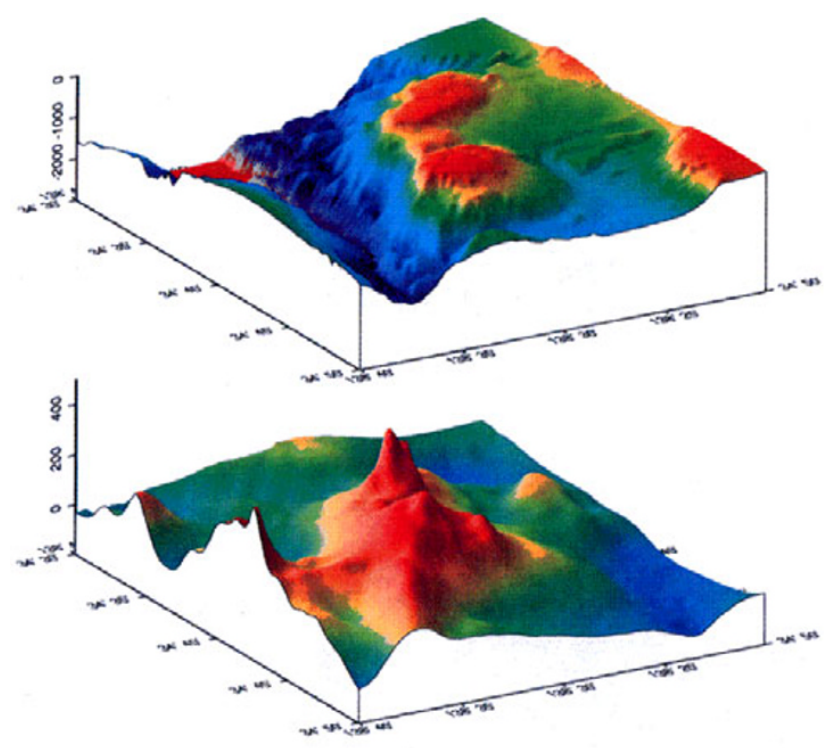

Case 1

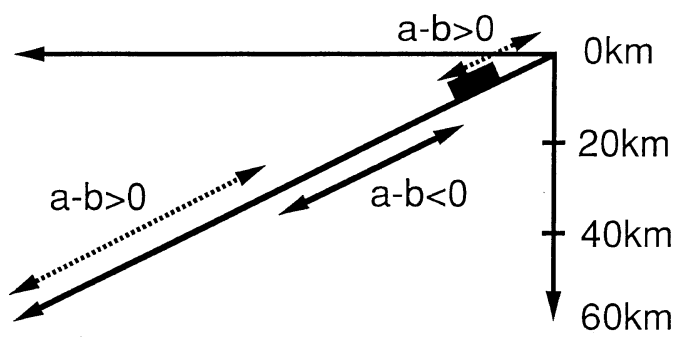

Case 2

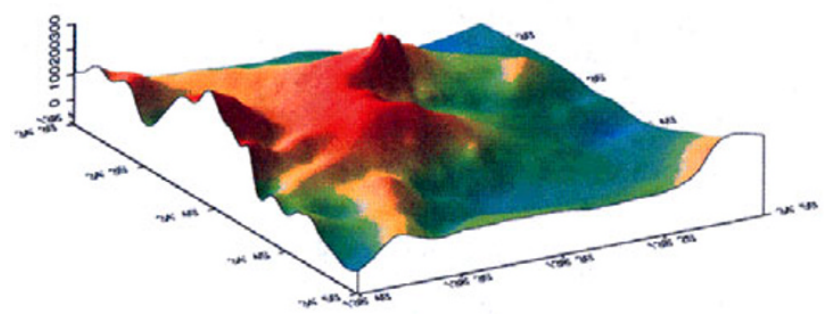

Fig. 3. Bird's-eye view of topography (top), pole-reduced magnetic anomalies (center), and magnetic anomalies (bottom). We are seeing these from the northeast toward the southwest. In the top figure, a deep trough and a pair of banks are easily recognized. Pole-reduced anomalies may seem to correspond to the banks, but their locations are slightly shifted toward the trough side.

normal stress in an otherwise decoupled zone (Scholz and Small, 1997).

\section{Numerical Simulation of an Interplate Earth- quake}

Our main concern is to find possible effects of the subducting seamounts, and we must first incorporate the seamounts into a simulation model. In this respect, we use a model of plate flexure due to the subduction of a seamount (Turcotte and Schubert, 1982; Scholz and Campos, 1995; Scholz and Small, 1997), and represent the seamounts in terms of additional normal stress. The inhomogeneity due to the seamounts is obviously three-dimensional, but here we approximate it as a two-dimensional one in our numerical simulation. Here we note that the effect of non-uniform normal stress on a seismic cycle was examined in the simulation study of BenZion and Rice (1995).

We now estimate the magnitude of the additional normal stress. Our preliminary analysis of the magnetic anomaly data has provided information on the size of the seamount; the width of the seamount base is in the order of $10 \mathrm{~km}$ and the height is a few kilometers, according to our modeling. Then the order estimation yields an additional normal stress of $10 \mathrm{GPa}$ (Scholz and Small, 1997). However, the

overriding plate in the Suruga trough area is composed of accretionary sediments (Le Pichon et al., 1996) and, hence, the flexural rigidity of the overriding plate would be lower than $3 \times 10^{21} \mathrm{~N} \cdot \mathrm{m}$ which was used in the paper of Scholz and Small (1997) for sediment starved arcs; here we adopt $3 \times 10^{20} \mathrm{~N} \cdot \mathrm{m}$. Also, our numerical simulation is based on a two-dimensional model, and if we compare the width of $10 \mathrm{~km}$ for the seamount base with the typical width of an interplate earthquake in the Suruga trough area, about 100 $\mathrm{km}$ (Ishibashi, 1981), the additional normal stress value of $1 \mathrm{GPa}$ would still be one order of magnitude too high. We therefore adopt $100 \mathrm{MPa}$ as an additional normal stress in our two-dimensional numerical simulation.

For numerical simulation, we use the version of rate- and state-variable friction law of Ruina (1983) and basically follow the numerical formulation used by Kato and Hirasawa $(1996,1997)$, in which a seismic damping term (Rice, 1993) is introduced and the stability of numerical computation (Rice, 1993) is carefully treated. The friction law is characterized by some parameters. Among them, the difference between friction parameters $a$ and $b$ controls seismogenic behavior; unstable slip occurs in a fault zone where $a-b$ is negative, referred to as a seismogenic zone. In our simulation, $a-b$ is taken positive at both shallow and deep zones, and negative at intermediate depth, as shown in Fig. 4.

The next question to be addressed is whether or not the seamounts are located in the seismogenic zone: from the 
standpoint of simulation, is the zone where the additional normal stress is exerted located inside or outside the area of the negative $a-b$ value? According to the experimental data (Blanpied et al., 1991), the $a-b$ value is positive at low temperatures as well as at high temperatures, resulting in a high seismicity zone at intermediate depth (Scholz, 1998). In the present case, the seamounts are supposed to exist at the depth range of 5-8 $\mathrm{km}$ along the plate interface. This depth range seems to be marginal and therefore we consider two typical cases as shown in Fig. 4; an inhomogeneous area is located outside the seismogenic zone in model 1 and inside in model 2. Interpretations of seismicity (Matsumura, 1997) and geodetic data (Yoshioka et al., 1993) in terms of plate coupling seem to support model 1.

\section{Results and Conclusions}

We describe the results for these two models. Figures 5(a), (b) show the time evolution of slip along the plate interface in model 1 without (Fig. 5(a)) and with (Fig. 5(b)) the additional normal stress zone. It is most notable that a slow slip, often referred to as a pre-slip, appears immediately before the main slip at distances of about $70-100 \mathrm{~km}$ measured from the

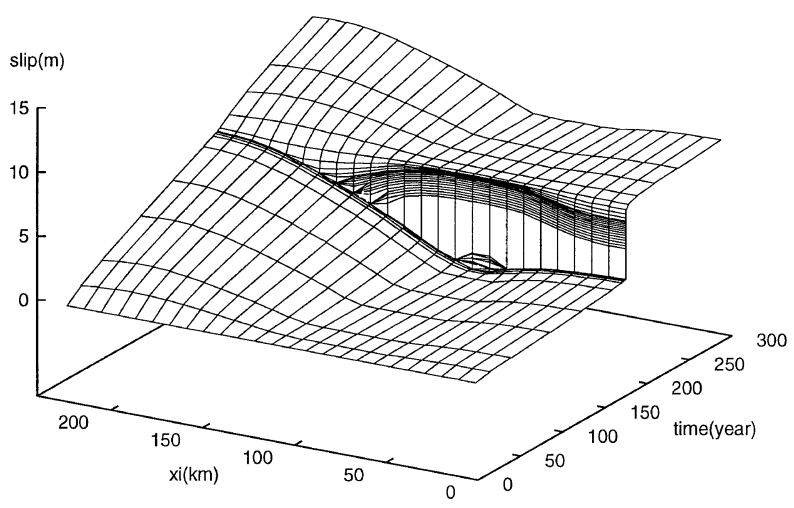

(a)

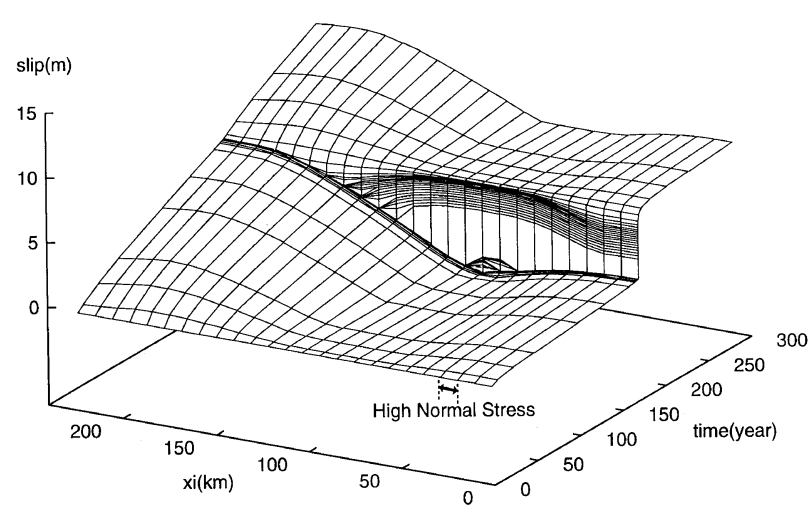

(b)

Fig. 5. (a) Time evolution of slip along the plate interface for case 1 shown in Fig. 4 but with no additional normal stress. The slip amount is shown for the distance in $\mathrm{km}$ along the plate interface and also for the time in years. A sudden main-slip corresponds to the occurrence of an interplate earthquake. A pre-slip can be seen immediately before the main slip. (b) Time evolution of slip for case 1 with an additional normal stress of 100 $\mathrm{MPa}$. trough axis along the plate interface. However, we can find no significant difference in pre-slip between these two cases. Instead, a slight difference can be seen in the amount of main slip and hence slow slip after the main slip in the zone near the trough axis. Such an effect becomes more marked as the additional normal stress increases. In an extreme case, the zone is locked during the main shock and significant slip occurs only after the main slip, indicating that the high normal stress area behaves as a barrier to the main slip.

In model 2 , we can find a clear effect of the additional

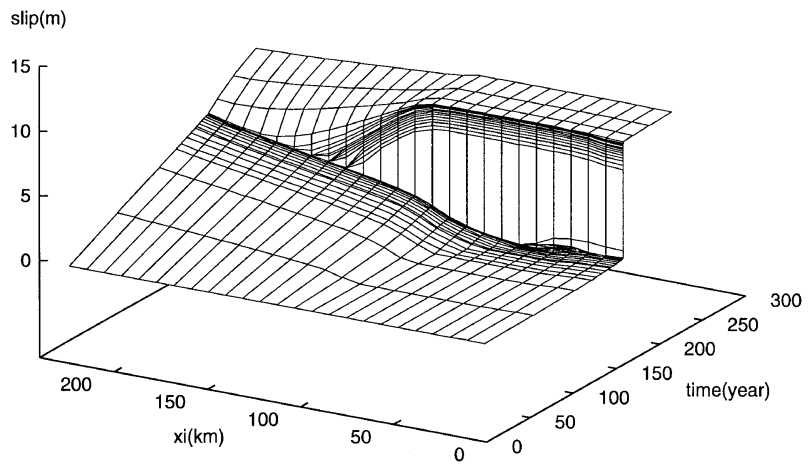

(a)

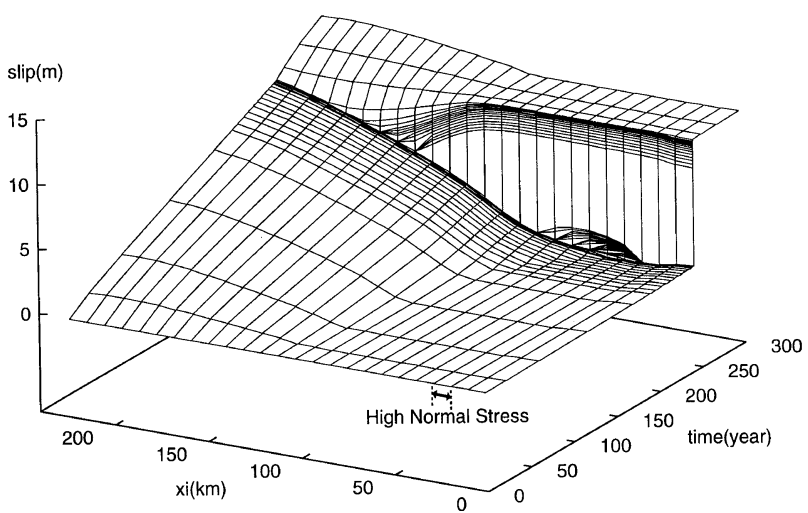

(b)

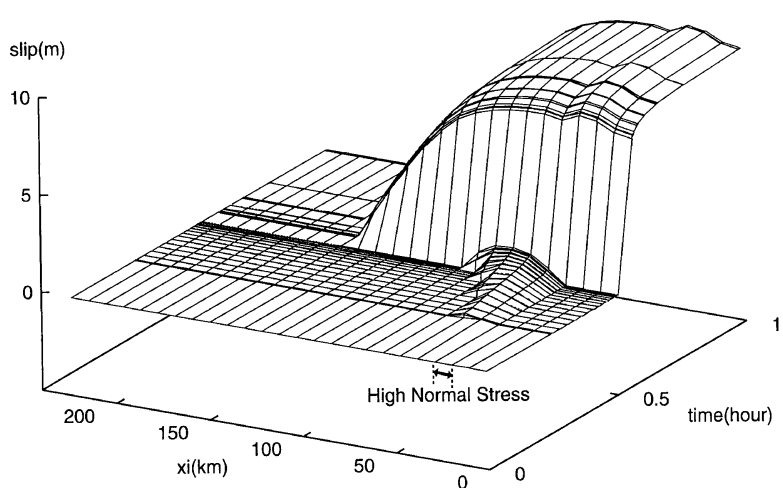

(c)

Fig. 6. (a) Time evolution of slip for case 2 with no additional normal stress (b) Time evolution of slip for case 2 with an additional normal stress of $100 \mathrm{MPa}$. In this case, a notable pre-slip initiates at the lower edge of the additional normal stress area and extends downward. (c) Characteristics of slip immediately before and after the main slip shown in (b). 
Table 1. Reccurrence intervals of an interplate earthquake for models 1 and 2 .

\begin{tabular}{ccc}
\hline Normal stress (MPa) & \multicolumn{2}{c}{ Recurrence interval (yr) } \\
\cline { 2 - 3 } & Model 1 & Model 2 \\
\hline 0 & 183 & 246 \\
100 & 171 & 264 \\
\hline
\end{tabular}

normal stress zone. In Fig. 6(a) (with no additional normal stress), we see a very small pre-slip before the main slip, but in Fig. 6(b) (with an additional normal stress of $100 \mathrm{MPa}$ ) a marked pre-slip appears. Figure 6(c) shows details of this pre-slip. The pre-slip seems to initiate near the lower edge of the high normal stress zone and extends downward until the occurrence of the main slip, which involves the high normal stress zone.

Concerning the recurrence interval of an interplate earthquake, it seems reasonable to suppose that the additional normal stress zone acts as a strong asperity and, hence, lengthens the recurrence interval (Scholz and Small, 1997). However, we can find no significant change with respect to the amount of additional normal stress in model 2 , and we even found the opposite result for model 1, as shown in Table 1. Also in this table, we find that the recurrence interval is longer in model 2 than in model 1 . So we presume that the recurrence interval is more likely to be controlled by the area of the seismogenic zone characterized by negative values of $a-b$. We should note, however, that this conclusion was obtained only for very limited cases.

The recurrence interval seems longer in the Tokai section than in the other sections along the Nankai trough, although arguments based on historical records must be carefully thought out (Ishibashi, 1981). Here we merely point out the possibility that such a difference may be a manifestation of a difference in the area of the seismogenic zone, although another mechanism has also been proposed (Le Pichon, 1996).

Finally we point out that information on spatial variation of plate coupling is crucially important in understanding the details of generation of an interplate earthquake at the Suruga trough. Fortunately, GPS measurements have been drastically intensified in the Tokai area with installation of GPS receivers at many sites. In the near future, details of plate coupling will be brought to light, most probably through estimates of the so-called back-slip amount. Also, with the development of a three-dimensional simulation technique, a more realistic model should be constructed to increase our understanding of the Tokai earthquake.

Acknowledgments. We are grateful to the magnetic survey team of the Hydrographic Department, Maritime Safety Agency, for providing us with the valuable magnetic anomaly data. We are also grateful to the National Research Center for Earth Science and Disaster Prevention for providing us with the earthquake data. We are thankful to Naoyuki Kato for his help in numerical simulation and for his thoughtful comments, and also to Tetsuzo Seno for his valuable comments.

\section{References}

Ben-Zion, Y. and J. R. Rice, Slip patterns and earthquake populations along different classes of faults in elastic solids, J. Geophys. Res., 100, 12,959$12,983,1995$.

Blanpied, M. L., D. A. Lockner, and J. D. Byerlee, Fault stability inferred from granite sliding experiments at hydrothermal conditions, Geophys. Res. Lett., 18, 609-612, 1991.

Cloos, M. and R. L. Shreve, Shear-zone thickness and the seismicity of Chilean- and Marianas-type subduction zones, Geology, 24, 107-110, 1996.

Dieterich, J. H., Modeling of rock friction 1. Experimental results and constitutive equations, J. Geophys. Res., 84, 2161-2168, 1979a.

Dieterich, J. H., Modeling of rock friction 2. Simulation of preseismic slip, J. Geophys. Res., 84, 2169-2175, 1979b.

Dieterich, J. H., Constitutive properties of faults with simulated gouge, in Mechanical Behavior of Crustal Rocks, edited by N. L. Carter, M. Freidman, J. M. Logan, and D. W. Sterns, pp. 103-120, AGU, Washington, D.C., 1981.

Honkura, Y., Y. Okubo, K. Nagaya, M. Makino, and S. Oshima, A magnetic anomaly map in the Japanese region with special reference to tectonic implications, J. Geomag. Geoelectr., 43, 71-76, 1991.

Ishibashi, K., Specification of a soon-to-occur seismic faulting in the Tokai district, central Japan, based upon seismotectonics, in Earthquake Prediction; an International Review, edited by D. Simpson and P. Richard, pp. 297-332, AGU, Washington, D.C., 1981.

Kato, N. and T. Hirasawa, Effects of strain rate and strength nonuniformity on the slip nucleation process: a numerical experiment, Tectonophysics, 265, 299-311, 1996.

Kato, N. and T. Hirasawa, A numerical study on seismic coupling along subduction zones using a laboratory-derived friction law, Phys. Earth Planet. Inter, 102, 51-68, 1997.

Lay, T. and H. Kanamori, An asperity model of great earthquake sequencies, in Earthquake Prediction; an International Review, edited by D. Simpson and P. Richard, pp. 579-592, AGU, Washington, D.C., 1981.

Le Pichon, X., S. Lallemant, H. Tokuyama, F. Thoué, P. Huchon, and P. Henry, Structure and evolution of the backstop in the eastern Nankai Trough area (Japan): implications for the soon-to-come Tokai earthquake, The Island Arc, 5, 440-454, 1996.

Matsumura, S., Focal zone of a future Tokai earthquake inferred from the seismicity pattern around the plate interface, Tectonophysics, 273, 271291, 1997.

Molnar, P. and P. Tapponier, Cenozoic tectonics of Asia, effects of a continental collision, Science, 189, 419-428, 1975.

Molnar, P., P. England, and J. Martinod, Mantle dynamics, uplift of the Tibetan Plateau, and the Indian monsoon, Rev. Geophys., 31, 357-396, 1993

Rice, J. R., Spatio-temporal complexity of slip on a fault, J. Geophys. Res., 98, 9885-9907, 1993.

Ruina, A. L., Slip instability and state variable friction laws, J. Geophys Res., 88, 10,359-10,370, 1983.

Scholz, C. H., Earthquakes and friction laws, Nature, 391, 37-42, 1998.

Scholz, C. H. and J. Campos, On the mechanism of seismic decoupling and back arc spreading at subduction zones, J. Geophys. Res., 100, 22,103$22,115,1995$.

Scholz, C. H. and C. Small, The effect of seamount subduction on seismic coupling, Geology, 25, 487-490, 1997.

Seno, T., The instantaneous rotation vector of the Philippine Sea plate relative to the Eurasian plate, Tectonophysics, 42, 209-226, 1977.

Stuart, W. D., Forecast model for great earthquakes at the Nankai trough subduction zone, Pure Appl. Geophys., 126, 619-641, 1988.

Tse, S. T. and J. R. Rice, Crustal earthquake instability in relation to the depth variation of frictional slip properties, J. Geophys. Res., 91, 9452-9472, 1986.

Turcotte, D. and G. Schubert, Geodynamics: Applications of Continuum Physics to Geological Problems, 450 pp., John Wiley, New York, 1982.

Yoshioka, S., T. Yabuki, T. Sagiya, T. Tada, and M. Matsu'ura, Interplate coupling and relative plate motion in the Tokai district, central Japan, deduced from geodetic data inversion using ABIC, Geophys. J. Int., 113, 607-621, 1993.

Y. Honkura (e-mail: yhonkura@geo.titech.ac.jp), Y. Nagaya, and H. Kuroki 